\title{
O Uso de Storytelling para Apoiar o Compartilhamento de Conhecimento
}

\author{
Roberta Salim¹, Angélica F.S. Dias ${ }^{1}$, Juliana B. S. França1, Bruno B. Lage ${ }^{1}$, Marcos \\ R.S. Borges ${ }^{1}$ \\ ${ }^{1}$ Pós-graduação em Informática - Universidade Federal do Rio Janeiro (UFRJ) \\ Caixa Postal 68.530 - 21.941-590 - Rio de Janeiro - RJ - Brasil \\ robertasalim@hotmail.com, brunobarboza@gmail.com, \{angelica, juliana.franca, \\ mborges\}@ppgi.ufrj.br
}

\begin{abstract}
Public schools in Rio de Janeiro have recently adopted an approach, which is essentially communicative, concerning teaching English. The use of group storytelling supported by technology is an effective way of collecting data related to moments shared by a group. When such stories are formalized, the tacit knowledge can also be observed, making reality known. By using a tool called Sofia, specially made for collecting information through stories, students are supposed to work collaboratively so that a certain result can be achieved.
\end{abstract}

Resumo. Escolas públicas do município do Rio de Janeiro adotou recentemente uma abordagem essencialmente comunicativa para o ensino de língua inglesa. A contação de histórias apoiada pela tecnologia é uma forma bastante eficiente de se colher dados relacionados a algo que foi vivenciado por um grupo de pessoas. Quando essas histórias são formalizadas, o conhecimento tácito também pode ser observado, fazendo com que seja possivel uma maior aproximação da realidade dos eventos. Através da Sofia, uma ferramenta especialmente criada para a recuperação de informações através de histórias, busca-se chegar a um resultado a partir da colaboração de um grupo de alunos.

\section{INTRODUÇ̃̃̃}

Há aproximadamente cinco anos, o município do Rio de Janeiro, Brasil, oferece aulas de língua inglesa para crianças do primeiro ao quinto ano do ensino fundamental. Anteriormente, esse segmento não possuía acesso ao estudo de uma língua estrangeira. Contudo, devido aos eventos esportivos da Copa do Mundo de 2014 e dos Jogos Olímpicos de 2016, ambos no Rio de Janeiro (Brasil), a necessidade de preparar os alunos para tais eventos tornou-se evidente e o foco seria a comunicação entre eles e os estrangeiros. Na perspectiva da obtenção de bons resultados, foram confeccionados livros para atender a esse público e adotou-se uma abordagem essencialmente comunicativa. Nessa abordagem, o professor assume o papel de facilitador do processo de aprendizagem, a fim de que seus alunos usem a língua alvo como meio de comunicação [Larsen-Freeman 2000].

Neste novo momento, as aulas expositivas seriam totalmente substituídas por uma abordagem diferenciada que exigiria dos docentes não somente um extenso conhecimento da modalidade escrita da língua, mas também da oral. Para tanto, o quadro de professores 
foi ampliado e estes foram submetidos a provas escritas e orais a fim de que a fluência do docente pudesse ser considerada.

Uma vez que a comunicação é o principal objetivo da abordagem adotada, o uso de ferramentais tecnológicos torna-se bastante pertinente para dar suporte a mesma.

Os avanços tecnológicos não somente criam novos hábitos, como também trazem novos conceitos e levam a novas formas de pensamento. Dentre tantas mudanças, o uso de computadores e dispositivos móveis em redes diversas destacam-se por ter promovido uma das mais radicais transformações sociais e comportamentais de todos os tempos.

A internet causou uma verdadeira revolução na vida dos cidadãos, conhecida como: Revolução da Internet, Revolução Digital, dentre outras [Fuks 2012]. Embora rápidas, essas mudanças ocorreram de forma contínua e foram marcadas por determinados períodos conforme os avanços tecnológicos. A Geração de Baby Boomers, compreendendo os que nasceram entre o fim da guerra mundial e o início dos anos de 1960, foi impactada pela televisão e valorização da juventude. A Geração X, abrangendo os que nasceram entre o início da década de 1960 e o fim da década de 1970, presenciou a popularização do computador pessoal, videogames e o início da Revolução da Internet. Já a Geração Y, ou Geração Digital, e a Geração da Internet, são as primeiras a crescer em um ambiente digital. Essas gerações, diferentes das anteriores, não precisaram se adaptar aos novos hábitos trazidos pelos computadores em rede visto que desde cedo já possuem contato com a internet.

O público alvo destacado neste artigo, jovens das últimas gerações mencionadas, apresentam um perfil bastante diferente das gerações anteriores, uma vez que têm acesso à informação com facilidade e rapidez; diferentemente do que ocorria há um tempo atrás quando os alunos precisavam ir até bibliotecas para acessar determinado conteúdo. Basta uma rápida pesquisa na Internet para encontrarem diferentes informações e conhecerem pontos de vista distintos sobre um mesmo assunto. Com isso, os jovens passaram a adotar uma postura investigativa diante das informações recebidas e a forma de aprender foi inteiramente modificada. Os jovens deste século trabalham o tempo todo conectados, compartilhando informação, atuando em conjunto e aprendendo com a colaboração de outras pessoas. Por isso, o método tradicional até então utilizado por muitas escolas precisou ser revisto e novas abordagens têm sido adotadas.

O ensino de línguas estrangeiras é fundamental para essa nova geração. Embora muitos alunos, sobretudo os da rede pública brasileira, não tenham condições financeiras de visitar outros países, eles certamente se comunicarão com pessoas de outras nações através da Internet. Para que essa comunicação fosse plenamente estabelecida, seria necessário que os usuários conhecessem o idioma uns dos outros. Entretanto, a fim de facilitar esse processo, a língua inglesa, por distintos fatores, acabou por ser a principal forma de comunicação entre habitantes de diferentes nações; ela passou a ser considerada língua franca.

Aproximadamente cinco anos se passaram desde que a nova abordagem foi adotada na disciplina de inglês nas escolas públicas da rede municipal do Rio de Janeiro. Contudo, os alunos precisaram adaptar-se a essa nova forma de aprender, uma vez que estavam habituados a um ensino mais tradicional. As aulas passaram a ser mais lúdicas, a interação e cooperação tornaram-se hábitos diários, diferentes mídias foram constantemente adotadas e a tecnologia passou a ser parte do conteúdo. Segundo Kumar (1996) ambientes educacionais centrados em promover interação entre os 
indivíduos, tendem a buscar estratégias de colaboração para estimular o grupo a buscar melhores resultados no processo de aprendizagem. Destaca-se neste cenário a evolução do conhecimento baseado no trabalho coletivo, e não somente no individual. Voltado para os aspectos sócio técnicos, vinculados não somente a tecnologia, como também às relações humanas [Nonaka et al 2009].

Os alunos analisados, que cursavam o quinto ano, fizeram parte das primeiras turmas a terem acesso a uma língua estrangeira desde o $1^{\circ}$ do ensino fundamental e foram os primeiros a experimentar a abordagem comunicativa na rede pública de ensino do município. Dito isso, viu-se a necessidade de obter-se um retorno por parte desses alunos a fim de que, através de relatos construídos por eles, conheçam-se os impactos causados pela abordagem no ensino da língua. Logo, a questão principal deste estudo é verificar a influência da abordagem comunicativa na aprendizagem da língua inglesa em escolas da rede municipal do Rio de Janeiro.

A fim de que os dados necessários fossem capturados de modo eficaz, utilizou-se a técnica de contação de histórias em grupo (group storytelling) que se originou de um dos meios mais utilizados para transmissão de conhecimentos, práticas e percepções pela humanidade: histórias. A história pode ser definida como uma narrativa - uma passagem de conhecimento, ou uma cadeia de eventos dito ou escrito em prosa ou verso [Valle 2003]. O group storytelling reforça a construção de conhecimentos e o compartilhamento de ideias através de narrativas com a formalização do conhecimento tácito. No caso dos alunos, buscam-se as narrativas de suas experiências e vivências. $\mathrm{O}$ uso da tecnologia serve como facilitador do processo de levantamento dos dados, mas também torna o momento mais significativo, prazeroso e memorável para as crianças.

\section{A INFLUÊNCIA TAYLORISTA/FORDISTA NA EDUCAÇÃO}

Para melhor compreendermos a situação da maioria das escolas no Brasil, faz-se necessário um breve relato histórico de tendências que influenciaram ou vêm influenciando as escolas.

De acordo com o estilo de produção em massa de Henry Ford, o trabalhador assumia tarefas simples e repetitivas que não exigiam muita qualificação de seus operários, pois não era necessário conhecer todo o processo no qual estavam envolvidos. O modelo de produção de carros bem como a forma como eram geridos influenciaram não somente a economia, mas a educação.

Segundo Ferreira (2013), as tendências pedagógicas conservadoras em todas as suas modalidades foram originadas pelos princípios tayloristas/fordistas. A divisão entre pensamento e ação, a organização e fragmentação dos conteúdos, a memorização como evidência de aprendizagem, a repetição, dentre outros, são apenas alguns exemplos da herança fordiana. As crianças não eram incitadas a pensar, contextualizar ou criticar. Não havia espaço para a criatividade. O conhecimento era apenas depositado nos alunos, que eram vistos como seres passivos, como máquinas que não possuem atividades cognitivas.

Embora o Fordismo date do início do século XX, algumas escolas, apesar de terem incorporado a tecnologia às suas práticas pedagógicas, ainda adotam um padrão instrucionista. De acordo com esse padrão, o computador é visto como o tradicional professor, que tem a função de fornecer informações e transmiti-las aos alunos. Apesar da tecnologia, o aluno ainda possui um papel inerte diante da máquina. Segundo Valente (2015), "a abordagem que usa o computador como meio para transmitir a informação ao 
aluno mantém a prática pedagógica vigente. Na verdade, o computador está sendo usado para informatizar os processos de ensino que já existem. Isso tem facilitado a implantação do computador na escola, pois não quebra a dinâmica por ela adotada."

Embora muitos esforços tenham sido feitos para que haja uma total mudança na educação, sabe-se que esse caminho é gradativo e muitas vezes lento. Algumas escolas no município do Rio de Janeiro têm procurado adotar novas posturas a fim de que seus alunos sejam amplamente atendidos, como o caso da abordagem comunicativa aplicada ao ensino de idiomas. Ainda assim, existe um longo caminho a ser percorrido.

\subsection{A ABordagem COMUNiCATIVA}

Embora a abordagem comunicativa seja inovadora no ensino de línguas, a mesma data da década de 1970: época em que os educadores começaram a questionar se estavam atingindo seus objetivos da forma correta. Alguns observaram que embora os alunos pudessem produzir frases gramaticalmente corretas em determinada lição, eles não eram capazes de se comunicar genuinamente fora de sala de aula. Outros perceberam que ser capaz de se comunicar exige mais que dominar estruturas linguísticas, isso requer que os alunos sejam capazes de executar funções, tais como: prometer, convidar, rejeitar convites, entre outros, de acordo com um determinado contexto [Larsen-Freeman 2000].

Seguem alguns dos princípios fundamentais da abordagem observados por Larsen-Freeman (2000) são: (a) a língua deve ser usada, sempre que possível, de forma autêntica e em um contexto real; (b) ser capaz de entender as intenções do falante ou do escritor é parte da competência comunicativa; (c) a língua alvo é um meio de comunicação e não objeto de estudo; (d) uma mesma função pode ter diferentes formas linguísticas; o processo de comunicação deve ser enfatizado em vez da forma; (e) alunos devem ser coesos e coerentes; jogos são importantes; o significado deve ser negociado; (f) trabalhar em pequenos grupos maximiza a prática comunicativa; (g) os alunos devem ter a oportunidade de expressar opiniões e ideias; (h) erros são tolerados e vistos como parte do desenvolvimento; o principal papel do professor é estabelecer situações a fim de que haja comunicação; (i) a interação motiva relações cooperativas entre os alunos e cria a oportunidade de negociação de significado; (j) o contexto social é essencial; aprender a usar estruturas da língua adequadamente é parte importante do processo comunicativo; (k) o professor atua como facilitador e como conselheiro durante as atividades; (l) na comunicação, o falante deve terá escolha não somente de o que dizer, mas de como dizer; a gramática e o vocabulário devem partir de funções, contexto situacional e dos papéis dos interlocutores; e (m) os alunos devem ter oportunidades de ouvir a língua como é usada na comunicação autêntica.

Se considerarmos as ideias de Ford e Taylor, e a abordagem comunicativa, fica evidente que há um imenso contraste entre o que era utilizado nas escolas municipais do Rio de Janeiro e o que tem sido realizado atualmente na disciplina de inglês. Outra importante questão refere-se à lacuna entre as metodologias abordadas por outras disciplinas e a abordagem sugerida especialmente para o ensino de língua inglesa; o que não indica que a forma de ensinar inglês seja superior a abordagem utilizada em outras matérias e vice-versa.

A comunicação deve ser autêntica em vez de inventada ou falseada. Dito isso, a tecnologia é fundamental, principalmente quando se leva em conta a internet, que é uma rica fonte de conhecimentos e um grande meio de comunicação entre pessoas de 
diferentes nacionalidades. Portanto, sempre que possível, deve-se fazer uso da mesma a fim de que os seus benefícios possam ser explorados e que os alunos sejam amplamente atendidos.

\subsection{A COLABORAÇ̃̃o E O GROUP STORYTELLING}

Estudos apresentam os "Sistemas Colaborativos", "Groupware", ou Computer Supported Cooperative Work (CSCW) como algumas nomenclaturas que designam o uso de tecnologias para o trabalho em grupo. Embora esses termos existam mesmo antes da web, eles estão relacionados a sistemas computacionais que apoiam a colaboração [Fuks 2012]. A última, CSCW, refere-se também a uma área de estudo que tem por base um modelo cujas dimensões apoiam um trabalho em grupo, o modelo 3C.

Ele é dividido em 3 (três) dimensões: comunicação, coordenação e cooperação. A comunicação refere-se à ação uma vez que, enquanto se comunicam, as pessoas negociam e tomam decisões. Já a coordenação, refere-se aos conflitos e organização das atividades. Muitas vezes, durante a cooperação, há a necessidade de renegociação, o que demanda comunicação e coordenação para a reorganização de tarefas. Nesse cenário, a questão da percepção é bastante relevante já que o indivíduo obtém feedback de suas ações e feedthrough das ações dos colegas [Fuks 2012]. Segundo Oliveira (2014), a diversidade de conhecimento, ou seja, diferentes níveis de conhecimento compartilhados em sala de aula, pode melhorar o processo de aprendizagem.

A fim de que o conhecimento seja compartilhado eficazmente é necessário que haja um foco interpretativo comum e que seu contexto seja estabelecido e compartilhado entre todos os membros. Logo, se um grupo de pessoas participou de alguma situação comum, esse contexto real pode auxiliar a entender melhor determinada situação. Esse conhecimento é chamado de tácito já que, em grande parte, ele está na mente das pessoas e não é registrado em documentos formais. Sendo assim, faz-se necessário capturá-lo e organizá-lo a fim de que possa ser (re)utilizado. Contudo, extrair e explicitar esse conhecimento não é uma tarefa simples. Para tal, pode-se utilizar a criação de histórias em grupo como uma ferramenta de registro poderosa nesse contexto compartilhado [Santoro et al 2006, 2013].

O Group Storytelling [Laporti et al 2009 e Lemos et al 2012] permite que as pessoas trabalhem em conjunto colaborativamente e pode ser apoiado pelas mais diversas tecnologias. As histórias podem ser uma abordagem poderosa para representar e fazer com que ideias multidimensionais sejam conhecidas; podem comunicar informação e emoção, tanto explícitas - Exemplo: referenciando documentos ou trechos destes quanto tácitas; e também permitem determinar contextos. Logo, quando os sistemas colaborativos trabalham com histórias, podem ajudar as pessoas a relatarem melhor os eventos e a apoiarem a extração de informações.

Quando uma história é contada, é fundamental que ela seja contextualizada, pois uma ação ou evento ganha significado de acordo com seu contexto. Ações individuais não são suficientes para que haja total entendimento de determinada história. O contexto e conhecimento contidos em histórias, principalmente nas que contêm diversas visões, são extremamente complexos. Para compreendê-los um pouco mais, é necessário perceber alguns conceitos, tais como os definidos em [Santoro et al 2013] e expostos a seguir: 
- Em uma atividade, o contexto é a soma de todo o conhecimento que os atores possuem dentro de certo assunto/conjuntura/tarefa.

- O conhecimento contextual é aquele que está relacionado ao presente, e é fundamental para o total entendimento de certa história. Tal conhecimento é despertado por certas situações e eventos e é determinado pelo foco do indivíduo.

- De acordo com certo contexto, o ator considera mais especificamente um subconjunto do conhecimento contextual. Esse conhecimento é então agrupado, organizado e estruturado em um contexto processual, que contém "partes de conhecimentos".

- Embora o conhecimento contextual exista na teoria, ele é considerado implícito e latente, e não é utilizado até que um objetivo ou intenção surja. Quando um evento acontece, ele ganha o foco da atenção do ator, e é então processado.

- Já que o contexto se modifica de acordo com a realização de determinada tarefa, ele pode ser considerado dinâmico; ele também é relativo pois varia de acordo com o foco de atenção. $\mathrm{O}$ foco determina o que o contexto deve conter, e o contexto limita o foco.

Definindo melhor o contexto pela ótica da interação dos diferentes conhecimentos, temse que contexto é um espaço.de conhecimento compartilhado, explorado pelos atores envolvidos na interação. Contudo, é necessário que a haja a distinção entre conhecimento contextual de cada ator e contexto compartilhado. O objetivo de uma atividade, por exemplo, pertence ao contexto compartilhado; cada ator precisa negociar, utilizando seu conhecimento contextual, para que o contexto processual seja construído colaborativamente. Já o contexto compartilhado age como um filtro, definindo que conhecimentos devem ser considerados (explicitados) e que conhecimentos não devem ser compartilhados (conhecimento implícito). O contexto processual contém todas as informações discutidas e aceitas (ou negociadas) por todos os envolvidos na interação. Quando um trabalho em grupo é realizado, o contexto compartilhado é fruto da negociação do conhecimento contextual dos atores envolvidos na atividade. Isso não significa que pontos de vista devam ser uniformizados. Entretanto, trabalhar colaborativamente exige constante comunicação, coordenação e cooperação, como visto no Modelo 3C.

O conhecimento coletivo pode ser um instrumento em potencial para a solução de problemas. Quando esse conhecimento é registrado, ele pode ser recuperado para que seu resultado seja melhor analisado e reaproveitado. Entretanto, quando esse conhecimento não é formalizado, não há como conhecermos suas implicações. A contação de histórias pode ser usada para que informações importantes sejam recuperadas. Nesse cenário, a história é um evento real vivido por determinado grupo de pessoas onde seus participantes/personagens devem expressar suas memórias sobre certos acontecimentos. Os eventos representam "partes de conhecimentos", que, quando conectados, resultam em uma história. Sendo assim, os ouvintes da mesma passam a ter acesso não somente aos eventos, como percebem todo o contexto que a envolve. Segundo Brooks (2003), contexto significa ver de um determinado ponto de vista. Este estudo busca conhecer o ponto de vista dos alunos em relação à abordagem essencialmente comunicativa proposta para a disciplina de inglês, através do storytelling [Salmon 2007], com o apoio da tecnologia. 


\section{APLICAÇÃo dE TÉCNICAS PARAA RECUPERAÇÃo COLETIVA DE CONHECIMENTO}

O conhecimento pode ser distinto de duas formas: conhecimento tácito e explícito. Podemos entender que o tácito é o conhecimento que cada indivíduo traz consigo, obtido através da experiência. Já o conhecimento explícito envolve a captura e representação dos fatos [Nonaka 1991]. Estudos mostram que a barreira no processo de gestão do conhecimento pode estar centrada na externalização, ou seja, na transformação do conhecimento tácito para explícito. No entanto, faz-se necessário pensar em formas, ferramentas ou métodos de compartilhamento de conhecimento que possam apoiar este processo.

Uma história, ou relato, pode apresentar diferentes pontos de vista de acordo com posicionamentos e crenças de certos indivíduos. O relator pode descrever a versão da história que guardou em sua mente após ter participado do evento ou acompanhado o seu desenvolvimento; ele também pode externar seu conhecimento tácito ou acrescentar algo a uma versão que já é conhecida. Embora pouco provável, já que o ser humano é normalmente tendencioso e movido por emoções, o relator também pode descrever aquilo que é real [Carminatti et al 2006]. Embora o storytelling seja uma ferramenta eficaz, nem sempre a versão relatada retrata a versão conhecida ou real. O conceito real é muito abstrato já que varia de indivíduo para indivíduo; o que é realidade para certa pessoa, não necessariamente é para outra. Com isso, existem técnicas que visam aproximar essas diferentes visões a fim de que se chegue o mais próximo possível do que de fato ocorreu.

Fuks e Pimentel (2012) propõem três maneiras de se alcançar a realidade: a técnica da entrevista, da dinâmica de grupo e da dinâmica de grupo apoiada por sistemas. As três técnicas sugeridas devem contar com um editor, cujo papel é ler os relatos e organizar uma versão segundo sua lógica pessoal. Com isso, surge uma nova discussão em relação à visão do editor. A primeira técnica é a da entrevista, onde os participantes do evento devem responder perguntas e, então, o editor combina as informações e produz o relato final. A segunda técnica busca capturar o conhecimento através de dinâmicas de grupo, onde os participantes se reúnem em um certo local físico e externam suas ideias através da interação. Essa dinâmica requer um facilitador e um relator; o facilitador deverá conduzir a discussão e o relator deverá tomar nota do conhecimento compartilhado e torna-lo acessível. Já na terceira técnica, que também conta com a dinâmica de grupos, os participantes interagem para enriquecer a narrativa apoiados pela tecnologia; o que pode tornar a interação síncrona ou assíncrona. Nesse caso, não há a necessidade de um relator.

Segundo Perret (2004), as narrativas com começo, meio e fim, são uma forma adequada de dizer o que aconteceu e, ao mesmo tempo, pode exteriorizar o conhecimento tácito do grupo, permitindo aos indivíduos realizarem suas contribuições, principalmente em ambientes educacionais.

Considerando o perfil dos discentes da atualidade, o presente trabalho fez uso da terceira técnica. Os alunos da rede municipal do Rio de Janeiro usaram a ferramenta Sofia [Lage e Quintanilha 2010], onde a história foi escrita através de fragmentos associáveis compartilhados a todos, com a possibilidade de serem comentados e editados de acordo com dimensões do domínio estabelecidas pelo facilitador. 


\section{FERRAMENTA SOFIA}

O arcabouço Sofia [Lage e Quintanilha 2010] foi especialmente elaborado para apoiar a técnica de group storytelling. Através da mesma, histórias podem ser contadas por diferentes atores de forma colaborativa. Sendo necessário que o participante seja o criador de uma história ou o mesmo seja convidado para uma. Dentro da história há definições sobre papéis. Além disso, a história pode ser definida como pública ou privada; ser gerenciada por um papel específico, normalmente o facilitador, ou ser auto gerenciável, em que todos os participantes dos mais diferentes papéis podem manipular toda a história; permitir a utilização de mídias; entre outras possibilidades. A Figura 1 mostra o cadastro de uma nova história.

Os usuários podem assumir diferentes papéis na história: contador, facilitador ou leitor. O contador é responsável pela construção da história, interação e cooperação com outros contadores - ele pode acrescentar fragmentos à mesma, bem como comentar os relatos de outros atores. O facilitador é responsável pela coordenação da história durante o seu processo; ele poderá participar diretamente ou indiretamente da história. Já o leitor, é responsável pela extração do conhecimento buscado ou pretendido da narrativa.

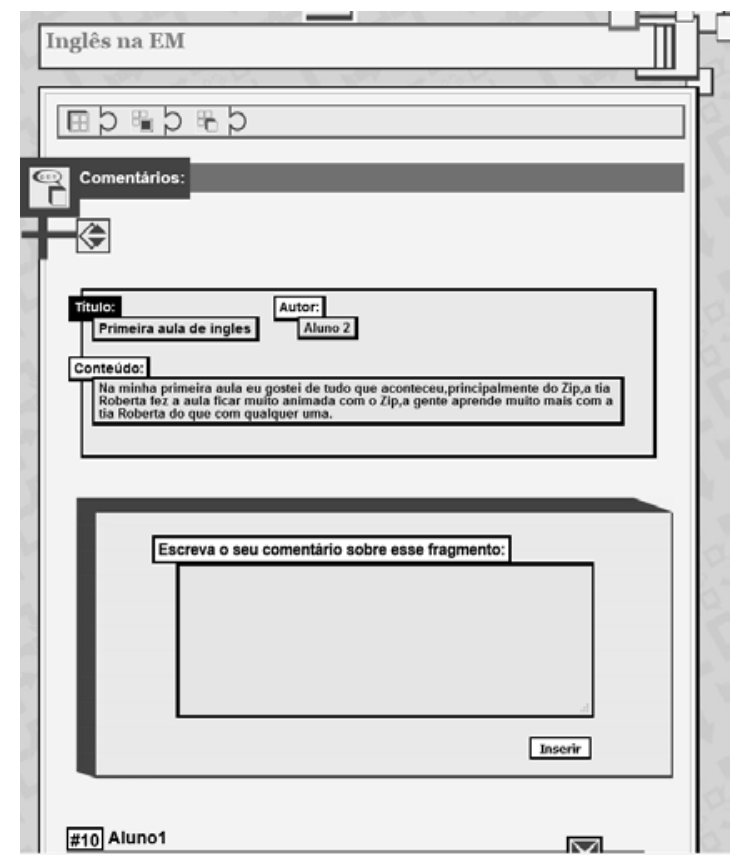

Figura 1: Criação de uma nova história na ferramenta.

Através do Sofia, várias histórias podem ser criadas (Figura 1). Além disto, uma mesma história pode conter diferentes narrativas (fragmentos), que podem conter inúmeros comentários. $\mathrm{O}$ facilitador tem acesso a todas as informações concernentes ao processo (Figura 2), tais como: histórias disponíveis; contribuitrômetro contendo número de participantes, número de fragmentos, número de comentários e mídias; e o participômetro, contendo o número total de contribuições da história e número total de contribuições acessadas.

A ferramenta pode ser facilmente usada e seu uso possui muitos benefícios. Contudo, seu aspecto colaborativo é essencial. O fato de várias pessoas poderem colaborar através de fragmentos e comentários torna a experiência extremamente rica, e faz com que resultados satisfatórios possam ser alcançados. 


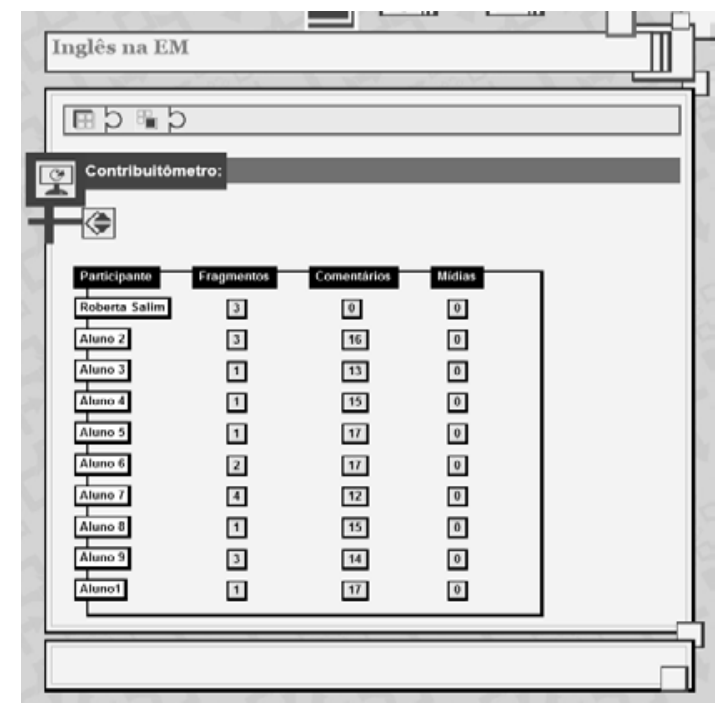

Figura 2: Participantes e quantitativo de suas contribuições.

Os indivíduos envolvidos na narrativa não são identificados através de nomes ou e-mails, mas números são atribuídos aos seus usuários. Dessa forma, o sigilo da autoria dos fragmentos e comentários é mantido.

\section{Método de Pesquisa Adotado}

O levantamento da influência da abordagem comunicativa na aprendizagem da língua inglesa em escolas da rede municipal do Rio de Janeiro, Brasil foi conduzido através de uma pesquisa descritiva. Segundo Gil (2008), este método de pesquisa permite descrever aspectos de determinados eventos através de técnicas de coleta de dados como a observação sistemática. Para a condução desta pesquisa foi executado um experimento que é descrito na próxima seção.

\subsection{Experimento}

Como o projeto de língua inglesa foi iniciado em 2011, os alunos que cursavam o quinto ano do ensino fundamental, foram os primeiros a utilizarem a nova metodologia e o novo material proposto especialmente para a disciplina de inglês. Por essa razão, um grupo de alunos do quinto ano foi selecionado para a pesquisa. A princípio, buscou-se envolver toda uma turma. Entretanto, por problemas operacionais com transporte, doze alunos foram convidados para o experimento, que foi realizado em um dos laboratórios da UFRJ; dos doze, apenas onze puderam comparecer.

Alguns dias antes do experimento, o projeto foi explicado aos alunos bem como seus objetivos. Eles ficaram cientes de que deveriam falar sobre as experiências vividas nas aulas de inglês, e que poderiam narrar tanto aspectos positivos quanto negativos de acordo com seus diferentes pontos de vista. Os alunos também foram alertados da importância de serem totalmente sinceros durante o projeto, expressando seus contentamentos e descontentamentos. Eles também foram informados de que deveriam não somente criar fragmentos como também interagir com seus colegas através de comentários. Também foi explicitado aos alunos como a ferramenta Sofia os auxiliaria no processo.

Embora, de acordo com o planejamento inicial, o uso das máquinas devesse ser individual, duas duplas precisaram ser formadas por questões técnicas. Com isso, sete 
alunos trabalharam individualmente em suas máquinas e duas duplas cada uma em uma máquina.

Os participantes do projeto foram devidamente cadastrados na ferramenta e passaram a ser identificados por números. Dessa forma, puderam acessar a ferramenta e selecionaram seus papéis na história - contador. A partir de então, eles puderam começar a criar seus fragmentos optando por estes serem classificados como um relato, fato ou descritor. Este último é voltado para quando alguém está detalhando algo em relação a outro fragmento existente. Isto ocorre por meio de associações.

O professor de inglês (que assumiu o papel de facilitador e editor), em certo momento, também interagiu com as crianças no ambiente. Embora três pessoas estivessem envolvidas no experimento, além dos alunos, em nenhum momento houve interferência em relação ao conteúdo das narrativas. $O$ facilitador, que em dado momento também postou fragmentos a fim de incitar as crianças a discorrerem sobre certos tópicos, também não exerceu muita influência sobre o conteúdo dos mesmos.

Os alunos participaram eficazmente da atividade, contribuindo com diversos fragmentos e fazendo diversos comentários. O participômetro mostrou um número final equivalente a cento e cinquenta e seis participações, sendo vinte o número de fragmentos criados e cento e trinta e seis o número de comentários postados. Levando-se em conta a média de idade dos alunos (entre 11 e 12 anos) a participação foi considerada muito boa.

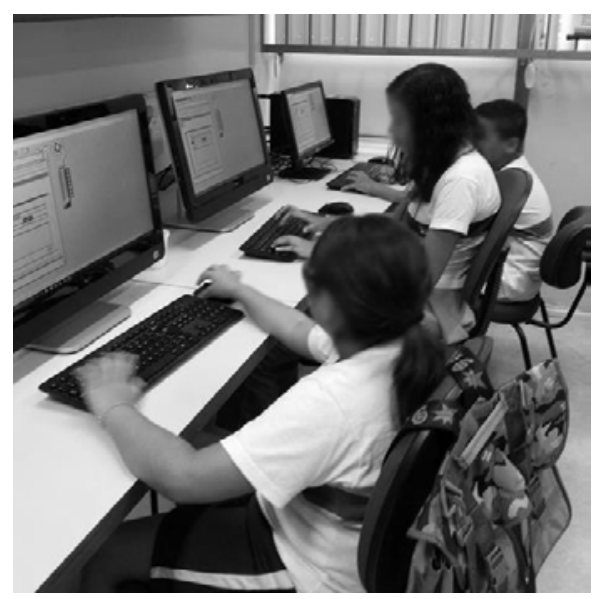

Figura 3: Participantes do estudo através do ambiente virtual Sofia.

Apesar de os alunos terem sido identificados por números a fim de diminuir a questão da influência, durante o experimento, as crianças notaram que os números haviam sido dados de acordo com suas respectivas posições. Com isso, algumas delas puderam identificar com quem estavam interagindo no ambiente virtual. Embora não esperado, as crianças sentiram-se confortáveis em fazer os comentários quando identificavam os colegas e também se divertiram com a questão da identificação. A Figura 3 mostra o ambiente onde o experimento ocorreu e os participantes do estudo.

Os alunos concluíram o experimento dentro do tempo esperado e se mostraram receptivas antes e após o projeto. Esboçaram várias vezes seus sentimentos em relação ao experimento através de palavras e gestos. A duração total do evento foi de quatro horas. 


\subsection{Dados Coletados}

Após a realização do experimento, todos os fragmentos e comentários feitos pelos alunos, através da ferramenta Sofia, foram coletados para a edição. As informações coletadas foram consideradas pelo editor e dimensões abaixo foram criadas. Percebeu-se que alguns pontos comuns foram considerados por diferentes alunos. Cento e cinquenta e seis contribuições foram relatadas, grande parte delas tratava dos seguintes assuntos: material utilizado, relação professor-aluno, uso do caderno/quadro em sala de aula, "sense of achievement e storytelling" associado à tecnologia.

O material utilizado pelos alunos é fornecido pela Prefeitura do Estado do Rio de Janeiro, Brasil. O uso desse material, somado à aplicação da abordagem, faz com que as aulas sejam dinâmicas e eficazes. Ainda assim, embora o uso do quadro branco não seja frequente, alguns alunos mencionaram seu uso como ponto negativo; o que reforça o descontentamento dos alunos com um estilo de aula mais tradicional. $\mathrm{O}$ desagrado com $\mathrm{o}$ uso do quadro e do caderno pode ser percebido em três dos vinte fragmentos e não é mencionado em nenhum dos comentários. A seguir, são expostos alguns fragmentos:

- FRAG7: "Na aula de inglês eu aprendi muita coisa legal com o Zip e a Stella [personagens] no livro de inglês. Eu gostava muito, já no caderno era muito ruim. Quando a professora X ensinava os nomes de lugar, comida e nome de pessoa era legal".

- FRAG12: "Olá eu estou contando a minha história do Inglês. Eu acho que o inglês não tem falha a não ser pelo simples fato de às vezes ter que copiar do quadro. Eu gosto da apostila porque tem muitas coisas legais como o Zip e Stella [personagens] $e$ seus companheiros que são muito legais. Se não tivesse que copiar seria muito mais legal e não teria defeito, na minha opinião. O inglês é a melhor matéria da escola”.

- FRAG20: "Gostava muito quando fazíamos trabalho em grupo, mas não gostava quando a tia escrevia o trabalho no quadro kkk [sic]".

Além do descontentamento com o uso do caderno, o FRAG20 apresenta um dos mais importantes princípios da abordagem comunicativa, que é a interação. É chamativo o modo como a aluna estabelece um contraste entre o trabalho no quadro e a atividade em grupo, ou seja, entre uma abordagem tradicional e a abordagem comunicativa. Esse é apenas um exemplo de feedback dentre muitos outros obtidos através do uso do storytelling apoiado pela tecnologia.

\subsection{Discussão dos Resultados e Limitações}

Os resultados coletados permitiram que alguns princípios da abordagem comunicativa fossem observados e, através da formalização do conhecimento tácito, ficou explicita a satisfação dos alunos em relação à abordagem comunicativa, e a insatisfação com um modelo mais tradicional de ensino. Eles mencionaram o fato de copiar matéria do quadro como algo negativo, embora não seja uma prática comum nas aulas de inglês. Mencionaram músicas, mídias, aspectos lúdicos, material, tecnologia e professor como pontos positivos. Alguns também expressaram seu desenvolvimento em relação à língua inglesa.

O número de participação dos alunos, considerando fragmentos e comentários feitos, foi excelente. A colaboração, coordenação e comunicação puderam ser percebidas durante o processo (modelo $3 \mathrm{C}$ ). O uso da tecnologia foi imprescindível e foi um agente 
motivador do experimento. Os alunos estavam extremamente felizes com o projeto e com toda a tecnologia que os cercava. Ficaram pasmados com os computadores do laboratório bem com a ferramenta.

O experimento realizado foi bem-sucedido uma vez que respostas foram fornecidas quanto à influência da abordagem comunicativa na aprendizagem de língua inglesa em escolas da rede municipal do Rio de Janeiro. Através das respostas com o ponto de vista dos estudantes, foi possível identificar que a abordagem comunicativa vem trazendo benefícios ao ensino da língua inglesa, contudo ainda são precisos mais experimentos com as demais turmas em formação para sua comprovação Com os resultados alcançados, pode-se apontar que o storytelling e, consequentemente o group storytelling, é eficaz no levantamento de dados com crianças, uma vez que é possível incluí-las em um ambiente desafiador, o que as coloca numa posição participativa através de seus relatos.

Apesar dos resultados obtidos, a pesquisa foi realizada com um pequeno grupo de estudantes. Ainda que o número tenha sido reduzido frente aos 20 alunos que totalizam a turma, os participantes foram escolhidos de forma a representarem o perfil da turma segundo seus conhecimentos. A fim de que houvesse uma maior acurácia em relação aos resultados, seria interessante que os próximos experimentos contemplassem todas as turmas, e que os mesmos fossem moradores de diferentes áreas do município.

Outro aspecto a ser aprimorado está relacionado à interferência da professora no processo; seu papel no experimento poderia ser revisto a fim de que os alunos se sentissem mais confortáveis ao narrarem suas histórias. Da mesma forma, para a obtenção de um resultado mais neutro, a edição poderia ser feita por uma pessoa não diretamente ligada ao processo/alunos. Outra opção seria que a edição fosse realizada por mais de uma pessoa e que resultados fossem comparados. Dessa forma, as realidades traçadas poderiam ser confirmadas.

Embora mudanças e melhoramentos possam ser realizados buscando uma maior acurácia nos resultados, esta pesquisa pode indicar novos caminhos para o desenvolvimento educação verificando a perspectiva dos alunos quando nas mais diversas disciplinas e mais uma vez combinar colaboração, tecnologia e uso do storytelling. Ademais, a eficácia do experimento poderá servir como esboço de modelo para que seja utilizada em diferentes áreas visando diferentes objetivos.

\section{CONCLUSÃo}

A fim de competir na economia global, os jovens precisam possuir conhecimentos e habilidades concernentes ao perfil exigido pelo Século XXI. No passado, deter conhecimento significava ser detentor de poder. Hoje em dia, o foco está não apenas no que se conhece, mas também no que as pessoas podem fazer com $o$ conhecimento/informação que pode ser acessado e nas habilidades interpessoais. As empresas buscam profissionais que saibam resolver problemas, que sejam comunicadores eficazes e conhecedores da tecnologia da informação. Há então uma urgência em que os alunos sejam preparados para atuar nesse novo tempo; e é papel da escola prepará-los até mesmo para profissões que ainda surgirão no futuro. Dito tudo isso, uma abordagem tradicional jamais se aplicaria a esse cenário; é necessário que haja interação, comunicação e colaboração.

Foi observado com os resultados alcançados neste estudo, que a abordagem 
comunicativa tem sido um meio eficaz em viabilizar o ensino da língua inglesa em escolas da rede pública do município do Rio de Janeiro, Brasil. Essa constatação foi possível através da aplicação do storytelling com o suporte tecnológico para a coleta desses dados. Ficou claro também que a contação de histórias aliada a tecnologia constrói um ambiente propício para o levantamento de impressões e críticas do público infantil. Como próximos passos desse trabalho é prevista a aplicação do storytelling através da ferramenta Sofia em outros cenários a fim de constatar sua aplicabilidade no que tange o envolvimento de crianças na melhoria de estratégias em domínios que sejam participantes.

\section{Agradecimentos}

Agradecemos a Escola Municipal do Rio de Janeiro por apoiar o projeto e permitir a aplicação da pesquisa. Também gostaríamos de agradecer a autorização de pais que permitiram que seus filhos participassem do experimento.

\section{Referencias}

Ferreira, Naura S. Carapeto. (2013) Gestão Democrática da Educação, Atuais Tendências, Novos Desafios. 8 ed. Sãp Paulo: Cortez.

Fuks, Hugo; Pimentel; Mariano (organizadores). (2012) Sistemas Colaborativos. Rio de Janeiro: Elsevier.

Gil, A.C. (2008) Como elaborar projetos de pesquisa. 4. ed. São Paulo: Atlas.

Kumar, V. S. (1996) Computer-Supported Collaborative Learning: Issues for research, In 8th Annual Graduate Symposium on Computer Science, University of Saskatchewan, Canada.

Lage, B. B.; Quintanilha, C. B. C. (2010) Sofia 2.0: A Maturação de um Arcabouço para Soluções de Group Storytelling através de uma Instanciação Avant-garde. Orientador: Marcos Roberto da Silva Borges. Rio de Janeiro: UFRJ/IM/DCC. Projeto Final de Curso (Bacharelado em Ciência da Computação).

Laporti, V, Borges, M., Barganholo, V. P. (2009) "Athena: A collaborative approach to requirements elicitation." Computers in Industry 60.6.367-380.

Larsen-Freeman. Diane. (2000) Techniques and Principles in Language Teaching. Oxford: Oxford University Press.

Lemos, J.; Alves, C.; Duboc, L.; Rodrigues, G. N. (2012) "A systematic mapping study on creativity in requirements engineering". In Proc. of the 27th Annual ACM Symposium on Applied Computing (pp. 1083-1088). ACM. Mar.

Nonaka, I. (1991) “The knowledge-creating Company”. Harvard Business Review, pp. 96-104.

Nonaka, I.; Takeuchi, H. (1997) Criação do Conhecimento na Empresa. Rio de Janeiro, RJ: Elsevier, 358p.

Oliveira, E. W.; Borges, M.R.S. (2014.) A Influência da Diversidade de Conhecimento no Processo de Aprendizagem Colaborativa. XI SBSC - Simpósio Brasileiro de Sistemas Colaborativo, Curitiba, PR.

Perret, R. ; Borges, M. R.S; Santoro, F.M. (2014) Applying Group Storytelling in Knowledge Management. CRIWG 2004. Springer-Verlag Berlin Heidelberg . 
Richards, Jack C; Rodgers, Theodore S. (2001) Approaches and Techniques in Language Teaching. Cambridge: Cambridge University Press.

Salmon, Christian.(2007) Storytelling: la machine à fabriquer des histoires et à formater les esprits. Paris: La Decouverte.

Santoro, Flávia Maria; Brézillon, Patrick. (2006) The Role of Shared Context in Group Storytelling. Computing and Informatics, v. 25, 497-522.

Santoro, Flávia Maria; BORGES, Marcos R. da Silva; SANTOS; Neide. (2013) Um Framework para Estudos de Ambientes de Suporte à Aprendizagem Cooperativa. Dissertação de Mestrado.

Valente, José Armando. Informática na Educação: instrucionismo X construcionismo. http://www.educacaopublica.rj.gov.br/biblioteca/tecnologia/0003.html Acessado em $05 / 08 / 2015$.

Valle, C., Raybourn, E.M., Prinz, W., Borges, M.R.S. (2003) Group Storytelling to Support Tacit Knowledge Externalization. Proc. of the 10th International Conference on Human - Computer Interaction. Crete, Greece. 